\title{
Efficacy and Safety of Focal Atrial Tachycardia and Typical Atrial Flutter Ablation in Nepal-A Single Center Experience.
}

\author{
Roshan Raut', Man Bahadur KC ${ }^{2}$, Murari Dhungana ${ }^{1}$, Mukunda Sharma ${ }^{2}$, Surakshya Joshi ${ }^{1}$, \\ Prashanta Bajracharya', Kunjang Sherpa', Mandita Chamlagain', Sujeeb Rajbhandari'.
}

${ }^{1}$ Department of Cardiology, Shahid Gangalal National Heart Center, (SGNHC), Bansbari, Kathamndu, Nepal.

${ }^{2}$ Department of Cardiology, Hospital of advanced medicine and surgery (HAMS), Dhumbarahi, Kathmandu, Nepal.

\section{Corresponding Author:}

Roshan Raut

Department of Cardiology, Shahid Gangalal National Heart Center, (SGNHC), Bansbari, Kathamndu, Nepal.

E-mail: rautroshan@hotmail.com

ORCID ID: 0000-0002-4207-3932

Submitted date: $17^{\text {th }}$ December 2020

Accepted date: $23^{\text {rd }}$ February 2021

Cite this article as: Raut R, KC M B, Dhungana M, et al. Efficacy and Safety of Focal Atrial Tachycardia and Typical Atrial Flutter Ablation in Nepal-A Single Center Experience. Nepalese Heart Journal 2021; Vol 18 (1): 25-28.

\section{Abstract}

Background and Aims: Atrial tachycardia is classified as focal atrial tachycardia or macro-reentrant atrial tachycardia. Macro-reentrant atrial tachycardia involves large circuit and is also called atrial flutter in which cavotricuspid isthmus dependent flutter, also called typical atrial flutter is the most common. The aim of this study is to report the efficacy and safety of catheter ablations of these arrhythmias, for the first time in Nepal.

Methods: This is a retrospective observational study of the patients who underwent electrophysiological study with ablation for focal atrial tachycardia and typical atrial flutters at Shahid Gangalal National Heart Center (SGNHC) from March, 2015 to February 2020.

Results: Altogether, 49 patients, 27 for focal atrial tachycardia and 22 for typical atrial flutter, underwent electrophysiology study with intent to ablation. In two patients, atrial tachycardia could not be induced, therefore 25 patients underwent ablation for atrial tachycardia. Out of 25 patients, the successful ablation achieved in 24 patients $(96 \%)$ with recurrence in three patients $(12 \%)$, with no major complications. Atrial tachycardia more commonly originated from right atrium than the left atrium $(68 \%$ vs. $32 \%)$. Among 22 patients who underwent cavotricuspid isthmus ablation for typical atrial flutter; successful ablation achieved in 21 patients $(95 \%)$ with recurrence in two patients $(9 \%)$ and a single case of access site hematoma. Counterclockwise flutter was found to be more common than clockwise flutter $(91 \%$ vs. $9 \%)$. Conclusion: In SGNHC, the ablations of focal atrial tachycardia and the typical atrial flutter has a high success and low complication rate.

Keywords: Cavotricuspid Isthmus Dependent Flutter; Focal Atrial Tachycardia; Typical Atrial Flutter.

DOI: https://orcid.org/10.3126/njh.v18i1.36776

\section{Introduction}

Atrial tachycardia is classified as focal atrial Tachycardia (AT) or macro-reentrant atrial tachycardia (MRAT) according to electrophysiological mechanisms. ${ }^{1}$ The mechanism of focal atrial tachycardia (AT) could be of automatic, triggered or micro-reentrant where as MRAT involves large circuit and also called atrial flutter. ${ }^{2}$ AT more commonly originates from the right atrium than the left atrium. In the right atrium, the common sites of origin of AT are crista terminalis, parahisian region and tricuspid annulus. ${ }^{3,4}$ In the left atrium, the common sites of AT origin are pulmonary vein ostia. ${ }^{4}$ The most common type of atrial flutter is typical atrial flutter, also called cavotricuspid isthmus dependent atrial flutter. Catheter ablation of focal atrial tachycardia and atrial flutter has become a standard practice as the first line treatment because of high efficacy and low complication rate. ${ }^{5,6}$ Although ablation of other supraventricular arrhythmias like atrioventricular nodal reentrant tachycardia and

@ Nepalese Heart Journal. Nepalese Heart Journal retain copyright and works is simultaneously licensed under Creative Commons Attribution License CC - By 4.0 that allows others to share the work with an acknowledge of the work's authorship and initial publication in this journal 
atrioventricular reentry tachycardia has been previously reported in Nepal, ${ }^{8,9}$ there is no published data regarding the safety and efficacy of atrial flutter and focal atrial tachycardia ablation in Nepal. Therefore, this study will be helpful to fill the gap regarding the knowledge of ablation of these arrhythmias in Nepal.

\section{Methods}

Patient Population

This is a retrospective observational study of the patients who underwent electrophysiological study with ablation for focal atrial tachycardias and typical atrial flutters at Shahid Gangalal National Heart Center (SGNHC) from March, 2015 to February 2020. A single primary operator was involved in the ablations. The data was collected from the procedural note; the discharge notes and the electrophysiology follow up log books. The proforma of each patient was filled with the collected data. The data was then analysed to evaluate the baseline characteristics, the immediate outcome including successful ablation and the complication, and follow up outcome including recurrences and repeat ablations. The baseline characteristics included age, sex, Left ventricular ejection fraction (LVEF), localization of atrial tachycardia, types and use of 3D mapping system. The presence of structural heart disease was evaluated by 12 lead electrocardiogram, transthoracic echocardiogram, and exercise stress testifdeemed necessary. Successful ablation of focal atrial tachycardia was defined as the termination of tachycardia during ablation and no recurrence at least $30 \mathrm{~min}$ after the last ablation lesion. Successful ablation of atrial flutter was defined as demonstration of bidirectional block across cavotricuspid isthmus even after termination of atrial flutter. The follow up outcome was assessed at one month, three to six months and longer if deemed necessary.

\section{Inclusion Criteria}

All symptomatic patients who had failed antiarrhythmic medicine or patient preference to ablation or suspected arrhythmias induced cardiomyopathy underwent catheter ablation.

\section{Electrophysiological Study and Catheter Ablation}

Atrial tachycardia ablation procedure was, in general, as follows: Four multipolar electrode catheters were placed in the high right atrium, the His bundle region, the right ventricle and the coronary sinus, respectively for the recording of endocardial electrograms and programmed stimulation. If AT did not develop spontaneously, it was induced by burst pacing or programmed stimulation from the high right atrium or coronary sinus. If at was still not induced, protocols were repeated with isoprenaline infusion. Once induced, Atrial tachycardia was diagnosed using standard electrophysiological criteria. The ablation of initial few cases were done conventionally without 3D mapping system, which was not available in Nepal at that time. The EnSite NavX system (St Jude Medical, St Paul, Minnesota, USA) was used for 3D mapping in rest of the cases. Once AT was induced, electroanatomical mapping of right atrium was done with the ablation catheter (usually $4 \mathrm{~mm}$ tip 6/7 Fr non-irrigated catheter). If no convincing early signal was found in the right atrium, trans-septal was performed and the left atrium was mapped. Ablation of right atrial tachycardia was primarily done with $4 \mathrm{~mm}$ tip 6/7 Fr non-irrigated catheters whereas that of Left atrial tachycardia with the $4 \mathrm{~mm}$ tip $7 \mathrm{Fr}$ Cool Flex (St. Jude Medical, St. Paul, MA, USA) catheter.

Atrial flutter ablation procedure, in general, was as follows: Three multipolar diagnostic catheters were placed in the His bundle region, the right ventricle and the coronary sinus. A Halo catheter was placed in the right atrium. Flutter ablations were generally done conventionally without a 3D mapping system. Ablation was performed during tachycardia, if the patient was already in atrial flutter before the procedure or if the atrial flutter could easily be induced. Otherwise, ablation was also performed during sinus rhythm. For ablations, mostly $8 \mathrm{~mm}$ tip non irrigated catheter were used, irrigated catheter were used in some cases. A continuous cavotricuspid isthmus (CTI) line was drawn starting from the ventricular aspect of the cavotricuspid isthmus till the ablation catheter dropped in the Inferior vena cava. The clean termination of atrial flutter (if ablation performed during tachycardia) and the bidirectional block across the CTI was defined as the successful ablation. For the right sided procedure, Heparin 3000 unit bolus was given without ACT monitoring, where as for the left sided procedure, bolus 3000 heparin with additional dose to keep ACT 250-300 seconds was given.

\section{Statistical Analysis}

Continuous variable was expressed as mean +- standard deviation or median and interquartile range if data was skewed. Categorical variable was expressed in percentage and compared with Chi Square. SAS software (version 9) was used for statistical analysis. This study was approved by the Institutional Review Board of SGNHC.

\section{Result}

From March 2015 till February 2020, a total of 49 patients underwent an EP study with intent to ablations; 27 patients for focal atrial tachycardia and 22 patients for typical atrial flutter. Baseline Characteristics has been shown in table 1 .

Table 1: Baseline characteristics:

\begin{tabular}{|lll|}
\hline & $\begin{array}{l}\text { Focal Atrial } \\
\text { Tachycardia }\end{array}$ & Atrial Flutter \\
\hline Patients (No) & $\begin{array}{l}25(2 \text { Excluded } \\
\text { being non Inducible) }\end{array}$ & 22 \\
\hline Mean Age (years) & 36 & 45 \\
\hline Male (\%) & $10 / 25(40 \%)$ & $17 / 22(72 \%)$ \\
\hline LVEF $<50 \%(\%)$ & $2 / 25(8 \%)$ & $2 / 22(9 \%)$ \\
\hline
\end{tabular}

Use of 3 D Mapping (\%) 23/25 (92\%) $\quad 1 / 22(4 \%)$ 
Table 2: Localization and outcome of Focal Atrial Tachycardia:

\begin{tabular}{|c|c|c|c|c|c|}
\hline \multicolumn{2}{|c|}{ Localizations } & $\begin{array}{l}\text { No of } \\
\text { Patients }\end{array}$ & $\begin{array}{l}\text { Success- } \\
\text { ful }\end{array}$ & $\begin{array}{l}\text { Compli- } \\
\text { cations }\end{array}$ & $\begin{array}{l}\text { Recur- } \\
\text { rence }\end{array}$ \\
\hline \multirow{4}{*}{$\begin{array}{l}\text { Right } \\
\text { Atrium }\end{array}$} & Cristal & 12 & 11 & no & 1 \\
\hline & $\begin{array}{l}\text { Tricuspid } \\
\text { Annulus }\end{array}$ & 3 & 3 & no & 0 \\
\hline & Parahisian & 1 & 1 & no & 1 \\
\hline & $\begin{array}{l}\text { Coronary } \\
\text { Sinus }\end{array}$ & 1 & 1 & no & 0 \\
\hline \multirow[t]{3}{*}{$\begin{array}{l}\text { Left } \\
\text { Atrium }\end{array}$} & $\begin{array}{l}\text { Pulmo- } \\
\text { nary vein } \\
\text { ostium }\end{array}$ & 4 & 4 & no & 1 \\
\hline & LA body & 1 & 1 & no & 0 \\
\hline & $\begin{array}{l}\text { Mitral } \\
\text { Annulus }\end{array}$ & 3 & 3 & no & 0 \\
\hline \multicolumn{4}{|c|}{ Successful Ablation } & \multicolumn{2}{|c|}{$24 / 25(96 \%)$} \\
\hline \multicolumn{4}{|c|}{ Recurrence During Follow Up } & \multicolumn{2}{|c|}{$3 / 24(12 \%)$} \\
\hline \multicolumn{4}{|c|}{ Repeat Ablation } & \multicolumn{2}{|c|}{$2 / 24(8 \%)$} \\
\hline \multicolumn{4}{|c|}{ Successful After Repeat Ablation } & \multicolumn{2}{|l|}{$2 / 2$} \\
\hline \multicolumn{4}{|c|}{ Complication } & \multicolumn{2}{|l|}{$0 / 25$} \\
\hline
\end{tabular}

Table 3: Types and outcome of Typical Atrial Flutter.

\begin{tabular}{lllll} 
Types & $\begin{array}{l}\text { No. of } \\
\text { Patients }\end{array}$ & Successful & Complication & Recurrences \\
\hline $\begin{array}{l}\text { Typical } \\
\text { Counter }\end{array}$ & 20 & 19 & $\begin{array}{l}\text { Groin hemato- } \\
\text { ma-1 }\end{array}$ & 2 \\
$\begin{array}{l}\text { Clock- } \\
\text { wise }\end{array}$ & & & & \\
$\begin{array}{l}\text { Typical } \\
\text { Clock- } \\
\text { wise }\end{array}$ & 2 & 2 & no & 0 \\
\hline
\end{tabular}

\begin{tabular}{ll|}
\hline Successful Ablation & $21 / 22(95 \%)$ \\
\hline $\begin{array}{l}\text { Recurrence During } \\
\text { Follow Up }\end{array}$ & $2 / 21(9 \%)$ \\
\hline Repeat Ablation & $2 / 21$ \\
\hline $\begin{array}{l}\text { Successful Ablation After } \\
\text { Repeat Ablation }\end{array}$ & $2 / 2$ \\
Complications & $1 / 22$
\end{tabular}

\section{Discussion}

Focal Atrial Tachycardia Demographic Characteristics

The mean age of the patients undergoing focal AT ablation was 36 years. Although studies show that there is no gender variation in the incidence of focal $\mathrm{AT},{ }^{10}$ female were more common than male $(60 \%$ vs. $40 \%)$ in our series, likely due to the effect of small sample size. All patients had structurally normal heart except two cases of Left Ventricular (LV) systolic dysfunction who were then diagnosed to be tachycardia induced cardiomyopathy. Medi et al. ${ }^{11}$ have described tachycardia mediated cardiomyopathy in up to $10 \%$ of patients undergoing catheter ablation for focal AT, with the LV function normalising in the majority following successful ablation. The occurrence of tachycardia induced cardiomyopathy was $8 \%$ in our series; and both the patients had a full recovery of LV function after successful ablation.

\section{Localization of Atrial Tachycardia}

Kistler et al. found that right sided AT occurred in $63 \%$ whereas left sided in $37 \% .{ }^{4}$ In our series, focal AT was found to be originating from the right atrium in $68 \%$ and from the left atrium in $32 \%$, similar to Kistler study. In the right atrium, the most common site was the crista terminalis $(70 \%)$, followed by tricuspid annulus (17\%). In the left atrium, the most common site was pulmonary vein $(50 \%)$, followed by mitral annulus (37\%), similar to other studies. ${ }^{3,12,13}$

\section{Efficacy and Safety}

The acute success rate of focal atrial tachycardia in several studies is in between 69 and $100 \% .{ }^{14}$ We have acute success rate of $96 \%$ comparable to other studies. The recurrence rate in our series was $12 \%$, similar to other studies. ${ }^{14,15}$ There was no complication noted in any of the AT ablation cases.

\section{Typical Atrial Flutter}

Demograhic Characteristics

The mean age of the patients undergoing typical atrial flutter ablation was 45 years, with male being more prevalent (72\%) similar to the other studies. ${ }^{16}$ Most of them were structurally normal heart, three patients had a known structural heart disease: one post Atrial septal defect closure, the second with mitral stenosis and the third post Aotic valve replacement with LV systolic dysfunction. Tachycardia mediated cardiomyopathy was seen in two patients, one of them had full recovery and another partial recovery of LV systolic function after CTI ablation of typical flutter.

\section{Atrial Flutter Type}

Majority of our patient (91\%) had counterclockwise typical flutter whereas only $9 \%$ had clockwise typical flutter, similar to other studies. ${ }^{17}$

\section{Efficacy and Safety}

Specter et al performed a systematic review of patients undergoing typical atrial flutter from 1990 to 2007 and found the single procedure efficacy rate of $92 \%$, multi-procedure efficacy of $97 \%$ with recurrence rate of $8 \% .^{7}$ In our series, the acute success rate of ablation of typical atrial flutter was $95 \%$ with recurrence rate of $9 \%$. There was no major complication except one case of access site hematoma.

\section{Conclusion}

In SGNHC, the ablations of focal atrial tachycardia and the typical atrial flutter has a high success and low complication rate.

\section{Limitations}

- The main limitation of this study is the small sample size.

- Being retrospective observational descriptive study, we cannot perform analysis for clinical significance. In the future, when we have bigger sample size, we will consider performing analytical study as well.

- Again because of retrospective study, we do not have data 
regarding the drugs used and left atrial size.

- Our basic protocol was to use $4 \mathrm{~mm}$ tip 6/7 Fr ablation catheter for the right sided procedure and St Jude $4 \mathrm{~mm}$ tip $7 \mathrm{Fr}$ coolflex ablation catheter for the left sided procedure. However, in some difficult right sided ablation cases, we have also used irrigation catheter, unfortunately, we do not have the data of such patients so as to correlate with the clinical outcome.

\section{Source of funding: None \\ Conflict of interest: None}

\section{References}

1. Saoudi N, Cosío F, Waldo A, et al. A classification of atrial flutter and regular atrial tachycardia according to electrophysiological mechanisms and anatomical bases; a statement from a Joint Expert Group from The Working Group of Arrhythmias of the European Society of Cardiology and the North American Society of Pacing and Electrophysiology. Eur Heart J 2001;22:1162-82. https://doi.org/10.1053/euhj.2001.2658

2. Chen SA, Chiang CE, Yang CJ, et al. Sustained atrial tachycardia in adult patients. Electrophysiological characteristics, pharmacological response, possible mechanisms, and effects of radiofrequency ablation. Circulation. 1994;90:1262-7.

https://doi.org/10.1161/01.CIR.90.3.1262

3. Morton JB, Sanders P, Das A, et al: Focal atrial tachycardia arising from the tricuspid annul us: electrophysiologic and electrocardiographic characteristics, J Cardiovasc Electrophysio. 2001;12:653-659.

https://doi.org/10.1046/j.1540-8167.2001.00653.x

4. Kistler PM, Roberts-Thomson KC, Haqqani HM, et al: P-wave morphology in focal atrial tachycardia: development of an algorithm to predict the anatomic site of origin, J Am Coll Cardiol. 2006;48:1010-1017. https://doi.org/10.1016/j.jacc.2006.03.058

5. Page RL, Joglar JA, Caldwell MA, et al. 2015 ACC/AHA/ HRS guideline for the management of adult patients with supraventricular tachycardia: a report of the American College of Cardiology/American Heart Association Task Force on Clinical Practice Guidelines and the Heart Rhythm Society. Circulation. 2016;133;e506-e574. doi: https://doi.org/10.1161/CIR.0000000000000311

6. Josep Brugada, Demosthenes G Katritsis, Elena Arbelo, et al. ESC Scientific Document Group, 2019 ESC Guidelines for the management of patients with supraventricular tachycardia The Task Force for the management of patients with supraventricular tachycardia of the European Society of Cardiology (ESC): Developed in collaboration with the Association for European Paediatric and Congenital Cardiology (AEPC), European Heart Journal, Volume 41, Issue 5, 1 February 2020, Pages 655-720, https://doi.org/10.1093/eurheartj/ehz467
7. Peter Spector, MDa, Matthew R. Reynolds, et al. MetaAnalysis of Ablation of Atrial Flutter and Supraventricular Tachycardia. Am J Cardiol 2009;104:671- 677. https://doi.org/10.1016/j.amjcard.2009.04.040

8. Raut R, KC MB, Rajbhandari S. et al. Radiofrequency ablation of right sided accessory pathway- 8 years experience at SGNHC. Nepalese Heart journal, 2011, Vol 8: 19-21. https://doi.org/10.3126/njh.v8i1.8332

9. Rajbhandari S, KC M, Raut R, et al. (1). Cardiac Electrophysiological Study \& Radiofrequency Ablation: Our Experience in Nepal. Journal of Advances in Internal Medicine. 2012;1(1):4-7. https://doi.org/10.3126/jaim.v1i1.5831

10. Yu-Feng $\mathrm{Hu}$ MD Gender differences of electrophysiological characteristics in focal atrial tachycardia. Am J Cardiol. 2009 Jul1;104(1):97-100. https://doi.org/10.1016/j.amjcard.2009.02.050

11. Medi C, Kalman JM, Haqqani H, et al. Tachycardia-mediated cardiomyopathy secondary to focal atrial tachycardia: longterm outcome after catheter ablation. J Am Coll Cardiol 2009;53:1791-7. https://doi.org/10.1016/j.jacc.2009.02.014

12. Kalman JM, Olgin JE, Karch MR, et al. Cristal tachycardias": origin of right atrial tachycardias from the crista terminalis identified by intracardiac echocardiography.J Am Coll Cardiol 1998;31:451-9. https://doi.org/10.1016/S0735-1097(97)00492-0

13. Hachiya H, Ernst S, Ouyang F, et al. Topographic distribution of focal left atrial tachycardias defined by electrocardiographic and electrophysiological data. Circ J 2005;69:205-10.

https://doi.org/10.1253/circj.69.205

14. Roberts-Thomson KC, Kistler PM, Kalman JM. Focal atrial tachycardia II: management. PACE 2006;29:769-78. https://doi.org/10.1111/j.1540-8159.2006.00433.x

15. Chen SA, Tai CT, Chiang CE, et al. Focal atrial tachycardia: reanalysis of the clinical and electrophysiologic characteristics and prediction of successful radiofrequency ablation. $\mathrm{J}$ Cardiovasc Electrophysiol 1998;9:355-65. https://doi.org/10.1111/j.1540-8167.1998.tb00924.x

16. Brembilla-Perrot B, Benichou M, MarcSellal J, et al. Women with atrial flutter differ from men. Archives of cardiovascular diseases suppliments. 2013;5(1):Pages 63-64. https://doi.org/10.1016/S1878-6480(13)71125-X

17. Kalman JM, Olgin JE, Saxon LA, et al. Electrocardiographic and electrophysiologic characterization of atypical atrial flutter in man: use of activation and entrainment mapping and implications for catheter ablation. J Cardiovasc Electrophysiol 1997;8:121-44.

https://doi.org/10.1111/j.1540-8167.1997.tb00775.x 